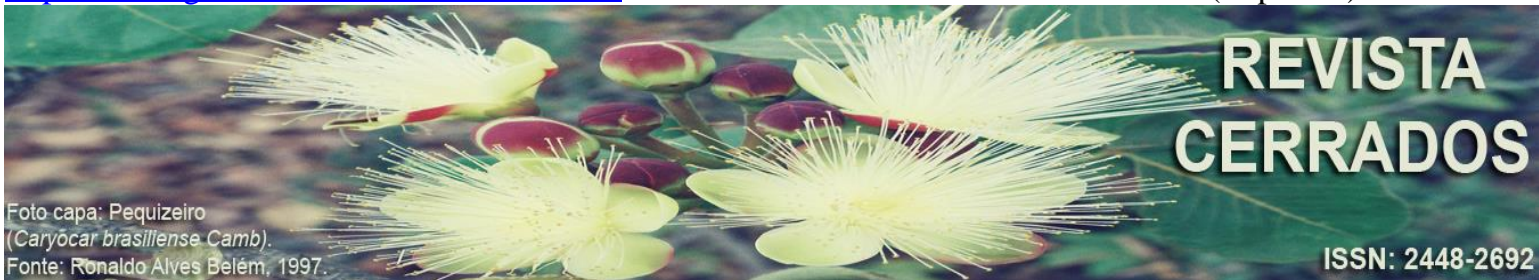

\title{
MEMÓRIA, AFEIÇÃO AO LUGAR E POLÍTICA: um olhar sobre o patrimônio em seus enredos derivados da geograficidade humana
}

\section{MEMORY, AFFECTIVE LINKS WITH PLACE AND POLITICS: a look at heritage in its plots derived from human geograficity}

\author{
MEMORIA, AFECTO AL LUGAR Y POLÍTICA: una mirada al \\ patrimonio en sus parcelas derivadas de la geograficidad humana
}

\author{
Rahyan de Carvalho Alves \\ Universidade Estadual de Montes Claros - UNIMONTES, Montes Claros, \\ Minas Gerais, Brasil. \\ E-mail: <rahyan.alves@unimontes.br> \\ José Antônio Souza de Deus \\ Universidade Federal de Minas Gerais - UFMG, Belo Horizonte, Minas Gerais, Brasil. \\ E-mail: <jantoniosdeus@uol.com.br>
}

\begin{abstract}
RESUMO
O objetivo deste trabalho é realizar uma análise sobre a constituição do patrimônio cultural de forma que se agreguem à problematização sobre o tema, visões que contribuam para o entendimento do estabelecimento da relação de pertencimento do Homem com o Lugar, na tentativa de obter uma compreensão do Patrimônio enquanto elemento de afeto e segurança para o sujeito no ambiente e no que concerne às conexões deste com o Estado. Para tanto utilizou-se basicamente como metodologia a reelaboração / retrabalhamento bibliográficos. Pôde-se refletir que o patrimônio cultural vem ganhando destaque em políticas governamentais que, em certa medida, valorizam a democracia cultural no que concerne às formas e as expressões que o Ser Humano recria e reinventa no Lugar e em seu imaginário, firmando o sentido do patrimônio na sociedade.
\end{abstract}

Palavras-chave: Lugar. Patrimônios Material e Imaterial. Patrimônio X Estado.

\section{ABSTRACT}

The objective of this research is to carry out an analysis on the constitution of Cultural Heritage in order to add to the to the views inherent to the theme, approaches that come close to the knowledge of the establishment of relationships of Man's belonging with the Place, in an attempt to obtain an understanding of heritage as an element of affection and security for 
ALVES. R. C.; SOUZA DE DEUS, J. A.

Memória, afeição ao lugar e política: um olhar sobre o patrimônio em seus enredos derivados da geograficidade humana

the subject in the environment and with regard to his connections with the State. For this purpose, bibliographic rework was basically used as a methodological tool. It was possible to reflect that Cultural Heritage has been gaining prominence in governmental policies that, to a certain extent, value cultural democracy in what concerns the valorization of the forms and expressions that human beings recreate and reinvent in their place and imaginary, establishing the sense of heritage in society.

Keywords: Place. Material and Immaterial Heritage. Cultural Heritage X State.

\section{RESUMEN}

El objetivo de este trabajo es llevar a cabo un análisis sobre la constitución del patrimonio cultural de manera que se agregue a la problematización del tema, visiones que contribuyan a la comprensión del establecimiento de la relación de pertenencia entre el Hombre y el Lugar, en un intento por obtener una comprensión del patrimonio como elemento de afecto y seguridad para el sujeto en el medio ambiente y con respecto a sus conexiones con el Estado. Para este propósito, el retrabajo bibliográfico se utilizó básicamente como metodología. Fue posible reflejar que el patrimonio cultural ha ganado importancia en las políticas gubernamentales que, en cierta medida, valoran la democracia cultural con respecto a la valorización de las formas y expresiones que el ser humano recrea y reinventa en su lugar y en su imaginario, estableciendo el sentido del patrimonio en la sociedad.

Palabras clave: Lugar. Patrimonio Material y Inmaterial. Patrimonio X Estado.

\section{INTRODUÇÃO}

A busca da compreensão da constituição do patrimônio cultural, atrelada à ligação do Sujeito com as suas marcas de vida nas paisagens, revela-se como uma tentativa de olhar para as experiências humanas que exprimem emoções e que correspondem a episódios da história do homem que se desenrolam em roteiros nem sempre livres para a sua atuação. Já os processos com vínculos políticos que fazem parte de todo um arsenal da obra humana, aparecem como significativos elementos dessa questão, e nessa perspectiva é que o patrimônio cultural foi visualizado de uma maneira humanizada, para que se pudesse entender o seu sentido/expressão de lembranças e estabilidade sociocultural, materializada certamente em um cenário social que é simultaneamente vivido, memorado e encenado, possibilitando, nesse contexto, uma constituição de sentidos topofílicos (TUAN, 2011).

Vale ressaltar que o termo patrimônio cultural ultrapassa as marcas visíveis de uma sociedade que tenta ser estável e que busca, em seus elementos tombados (reconhecidos e regulamentados), enraizar-se no Lugar, na perspectiva de se preservar e conservar uma 
ALVES. R. C.; SOUZA DE DEUS, J. A.

Memória, afeição ao lugar e política: um olhar sobre o patrimônio em seus enredos derivados da geograficidade humana

história, um momento, alguma lembrança. Por isso, retornar no tempo em outros gradientes sóciotemporais se faz tão difícil na discussão do patrimônio, pois é preciso qualificá-lo e decodificá-lo em diferentes óticas. Dessa forma, o objetivo deste trabalho é realizar uma análise sobre a constituição do patrimônio cultural de forma que se agreguem à problematização sobre o tema, visões voltadas à compreensão da relação de pertencimento do homem ao Lugar, na tentativa de se obter uma compreensão do patrimônio enquanto elemento de afeto e segurança para o sujeito no ambiente e de ligação deste ao Estado. Para tanto, utilizou se como procedimentos metodológicos essenciais a reelaboração / retrabalhamento bibliográficos.

\section{Formação do Patrimônio histórico: para além de um olhar político}

Para desenvolver as reflexões apontadas, previamente faz-se necessária uma análise histórico-geográfica sobre o Patrimônio Histórico. Podemos iniciar tal resgate histórico demarcando por Gonçalves (2002) onde destaca que o patrimônio se confunde com a ideia de propriedade, mesmo que ele esteja hoje e sendo crescentemente vinculado à dinâmica dos acontecimentos de caráter político, estético, psicológico, cultural, e observandose que são distintos os valores atribuídos ao ambiente, aos objetos e às suas formas de socialização de atributos que, em seu conjunto, representam a relação social que organiza o Espaço e o Homem (FUNARI \& PELEGRINI, 2006).

É sugestivo pontuar ainda que antes de reconhecer o termo patrimônio, inicialmente se utilizou e ainda se utiliza o termo Monumento alusivo a "Monumentum", derivado de "Monere" que significa advertir, lembrar, aquilo que traz lembrança de alguma coisa, fato ou lugar; e que agrega elementos que possam remeter a lembranças (CHOAY, 2006). O monumento seria uma informação social provocada pela emoção em uma memória que é viva ou insiste em estar presente. E é pertinente resgatar, nesta perspectiva, a ponderação de Choay (2006) sobre o sentido primordial do termo monumento, que é destacado como aquilo que foi edificado por uma comunidade de indivíduos para rememorar algo ou fazer tal coletividade voltar a tempos pretéritos e reviver etapas de uma vida as quais envolveram experiências de várias pessoas, testemunhando traços de uma cultura, modos de vida e percepções de sequências políticas e sociais; bem como contribuindo para a formação e 
ALVES. R. C.; SOUZA DE DEUS, J. A.

Memória, afeição ao lugar e política: um olhar sobre o patrimônio em seus enredos derivados da geograficidade humana

sustentação da identidade do homem e mediação dos conflitos de uma vida que tende, a todo o momento, a ser compartilhada (ICOMOS, 2007).

A carta de Veneza, a propósito, redigida no ano de 1964, para a Conservação e o Restauro dos Monumentos e dos Sítios, no seu Artigo $1^{\circ}$ destaca que o conceito de monumento extrapola o simples trabalho do arquiteto; ele vai além do enquadramento de cenas excepcionais do urbano e do rural. Ele se aplica onde se encontram evidências particulares de uma civilização; seja a sua aplicação direcionada a grandes obras de artes, ou a obras modestas do passado, desde que estas tenham adquirido "[...] significado cultural com a passagem do tempo" (ICOMOS, 2007, p.02).

Mas o ato de reconhecer um monumento, uma obra e seu valor, seja no sentido de colecioná-la, guardá-la ou expô-la, antecipa o que se conhece como Monumento(s) Histórico(s), pois estes remeteriam às obras e elementos destacados em museus. É pertinente observar, aliás, que a arte de colecionar surgiu no final do século III a.C., entre a morte de Alexandre III (356 a.C. - 323 a.C.) e a formação do Império Romano. Nesse período, o povo grego destacava-se como a elite culta, pois as campanhas, em batalhas, de Alexandre contribuíram para a ampla difusão da cultura helênica na Antiguidade clássica. E é partir dessa época, a escultura e a pintura tornaram-se cada vez mais realistas, tratando das paixões, do sofrimento humano com as perdas nas guerras, dentre outros temas (CHOAY, 2006).

Para se ter uma devida noção do aparecimento de esculturas, edifícios, monumentos, Choay (2006) destaca que em Roma, entre 146 a.C, muitos batalhões e exércitos como o de Átalo II Filadelfo (220 a.C. - 138 a.C.), rei de Pérgamo, ofereciam estátuas em oferenda aos deuses da mitologia. Pode ter se dado aí o nascimento simbólico e material do objeto da arte e daí ter se derivado, o hábito de colecionar tais objetos, inicialmente, como forma de respeito aos deuses e, posteriormente, como símbolo de poder e dominação na sociedade, ou seja, como um elemento de demonstração de grandeza social e imponência militar. E é a partir daí que os objetos e monumentos gregos expostos pelos exércitos romanos começam, vagarosamente, a adentrar algumas residências, embora seu "status" mude quando as obras preservadas como tesouros no interior dos templos começam a ser expostas à vista de todos, nas ruas e espaços abertos.

Dando-se um salto na história, mas analisando este mesmo recorte territorial, vale notar que os Monumentos renascem em Roma, por volta do ano de 1420, com eventos que 
ALVES. R. C.; SOUZA DE DEUS, J. A.

Memória, afeição ao lugar e política: um olhar sobre o patrimônio em seus enredos derivados da geograficidade humana

marcaram a sociedade, como o exílio do Papado em Avignon (1305-1377) e depois o Grande Cisma (1379-1417), eventos em que a Europa se configurou como um continente dividido em blocos rivais, disputando poder, mas após conflitos é escolhido Martinho V (Otto de Colonna, 1368-1431) como Papa em Roma, ou seja, nesse momento histórico, a Igreja Católica restabelece a sede do papado na "Cidade Eterna", tendo como uma das suas intenções ressalte-se (!) - buscar recuperar os monumentos locais, destruídos e não conservados (NASCIMENTO, 2011).

Mas, se observa um progressivo esvaziamento da função memorial do monumento durante os anos seguintes, e podemos assinalar alguns fatores para tentar explicar tal realidade. Primeiramente, no período histórico, sobretudo entre 1300 e 1650, na Europa, busca-se reviver a cultura greco-romana e isto, embora tenham ocorrido avanços consideráveis no campo da arte, literaturas e de diversas Ciências, esse momento em que se supera a herança clássica se caracteriza essencialmente por uma postura de oposição ao divino e ao sobrenatural que impregna a cultura da Idade Média. Verifica-se efetivamente que os trabalhos deste período (do Renascimento), na arquitetura, por exemplo, a ocupação do espaço do edifício passa a se relacionar a formas de organização baseadas na exatidão científica (sobretudo, da matemática) tendo, neste momento, ocorrido à utilização maior dos arcos, da escultura e da pintura (LIMA, 2008).

O artista não se configurava, então, simples observador de um mundo que expressaria a grandeza de Deus, mas proclamava, ao contrário, o seu sentimento, valendo-se de uma compreensão científica, para que sua obra não fosse apenas admirada pela sua beleza, uma vez que a marca do individualismo e da racionalidade estava, aí, claramente enunciada. Faz-se necessário ressaltar, contudo, que este movimento foi extremamente elitista, privilegiando os detentores de bens e colecionadores de obras que tinham um apreço pela arte gótica, além de ser um período em que as "[...] novas condições tecnológicas, possibilitaram a difusão da arte e do conhecimento por toda Europa e, posteriormente, pelo mundo" (LIMA, 2008, p.02).

Uma segunda questão a ser localizada nesse período diz respeito à dissociação que muitos realizaram do processo psíquico da visão de sociedade-mundo que o Monumento apresenta, principalmente se o processo de sua conservação não tivesse um referencial histórico, desprovido de uma relação de intensidade de tempos, aliado à ausência de um 
ALVES. R. C.; SOUZA DE DEUS, J. A.

Memória, afeição ao lugar e política: um olhar sobre o patrimônio em seus enredos derivados da geograficidade humana

arsenal da arte e do conhecimento. E podemos perceber que os monumentos eram, então, quase sempre ligados a lembranças literárias, ao lirismo e seus autores medievais, e nesta época, o interesse artístico-cultural pelos monumentos da Antiguidade era atribuído ainda à elite do "Quattrocentos" (CHOAY, 2006; COSTA, 2009) - à qual pode se associar, ao grupo que tentava vincular a imagem do Homem a um sentimento de autoconfiança, numa sociedade que se tornava cada vez mais complexa em termos econômicos e socioculturais.

Para o clero do século VII, ou até mesmo do século XII, o mundo antigo era tido como impenetrável e, muitas vezes, indecifrável em suas obras. E Choay (2006) destaca que realmente elas eram percebidas como de difícil decodificação, pois os territórios romanos ou romanizados, tornaram-se cristãos e as expressões literárias perderam os seus referenciais iniciais. Porém, entender a ideia, a essência e a sensibilidade cognitiva pelos monumentos apenas pela abordagem literária, em seu formato e compreensão de arte, é questionável, pois, na passagem do século XIV para o XV, abordagens mais sensíveis, emocionalmente chamativas, feitas pelos homens da arte foram destacadas. Neste momento trava-se um diálogo entre os artistas e os humanistas; no qual o olhar do artista busca ensinar ao outro a ver a obra por “[...] todos os ângulos da expressão da humanidade em seu contexto histórico intelectual, logo os humanistas relevam, clareiam as suas expressões aos arquitetos e aos escultores numa perspectiva mais histórica" (CHOAY, 2006, p.49).

A integração descrita entre os humanistas e os artistas foi importante para a Europa, principalmente em Roma, pois entre os séculos XIII e XV, o continente necessitava se reorganizar depois das sucessivas destruições que sofreu com ataques no seu território. E nesse contexto é que um profícuo processo de canteiros de obras romanas se materializa na tentativa de construir uma nova sociedade. Porém, um dilema central se apresentava, então, em relação aos monumentos construídos: as formas de embelezamento eram percebidas em dois vieses: um perfil moderno ou a permanência das obras que ali se firmavam, não ocorrendo uma visão de intermediação entre as formas e compreensão de artes de tempos e períodos distintos (GONÇALVES, 2002).

E é neste momento ainda que os humanistas se apresentam como os protetores de alguns monumentos, principalmente, através do uso das literaturas que alavancaram o prazer pela arte, provocando assim, a conservação de algumas obras da Antiguidade. Esses atores assumem o amor e gosto pelas obras como maneira de conservá-las, sendo analisados alguns 
ALVES. R. C.; SOUZA DE DEUS, J. A.

Memória, afeição ao lugar e política: um olhar sobre o patrimônio em seus enredos derivados da geograficidade humana

móveis e edifícios, além de esculturas, moedas, dentre outros objetos colecionados (por príncipes, principalmente); os quais foram conservados em jardins, residências e nas antecâmaras. E é dessa forma também que um novo espaço geográfico para a arte e o monumento no século XVI nasce: a galeria (CHOAY, 2006).

Após 1430, os humanistas, em especial os da corte pontifical, tendem a conservar e proteger os monumentos romanos, seja por sua representatividade artística ou pelo simples gosto da coleção que surge com um propósito de preservar os monumentos e, daí, promover medidas de "restauração" dos antigos edifícios contra as múltiplas agressões que estes sofreram diante da nova cidade de Roma que estava se erigindo (NASCIMENTO, 2011).

Nesse contexto, as ações políticas e econômicas ligadas à necessidade de embelezar e modernizar a cidade de Roma, com o advento do alargamento de ruas, construções de estabelecimentos comerciais, dentre outros, promoveram certa demolição de alguns monumentos e, com isso, paralela e contraditoriamente, tivemos, também, o surgimento da preservação das Antiguidades. Para garantir medidas de segurança para a perpetuação das ações de modernização de Roma, os técnicos urbanistas e arquitetos pontuavam alguns monumentos para preservação, "maquiando" a ideia de destruição. E com este processo, a relação de preservação da história, da arte e da conservação dos monumentos, principalmente arquitetônicos, aparece em pequenas migalhas de obras ao se comparar com a grandiosidade de monumentos que a cidade detinha (CERQUEIRA, 2006).

Já na França, os monumentos constituíram parte de uma história que energizava um país que queria revigorar o seu perfil nacionalista, embora a modernização também fosse encarada como necessária, então, passou por um processo de modernização, e ao mesmo tempo entendendo a importância dos monumentos históricos, a política de urbanização não se preocupava com o conjunto destas obras em sua malha urbana, mas destacava pequenos monumentos individuais (CHOAY, 2006).

Numa outra vertente de discussão que julgamos pertinente de ser problematizada, é relevante assinalar que os prazeres estéticos da arquitetura se renovam, mas o passado e o presente devem ser históricos, e construídos pelos olhares e julgamentos dos outros. A cidade antiga, velha, histórica, como muitos falam, não deve, assim, ser vista como obra intocável, mas, sim, visualizada como um processo de constantes idas e vindas à memória do homem, dentro e fora do circuito da sua vida, mediada pela sua atividade diária, pela simples e, ao 
ALVES. R. C.; SOUZA DE DEUS, J. A.

Memória, afeição ao lugar e política: um olhar sobre o patrimônio em seus enredos derivados da geograficidade humana

mesmo tempo, complexa tarefa de existir. Aliás, as cidades, bairros ou centros urbanos são sim, museus, sejam eles, pequenos, interioranos ou situados em grandes metrópoles, pois vale demarcar que a forma de cada um destes centros urbanos é reconhecida, ou deveria ser como uma obra de arte (CERQUEIRA, 2006).

E com o desenvolvimento das ações dos arquitetos e de suas reformulações paisagísticas nos monumentos, uma questão sobre a qual se pode refletir - inclusive nos dias atuais (!) -, é o cuidado que se deve ter no desenvolvimento de um processo de restauração, no sentido de se buscar respeitar e apresentar com fidelidade as marcas de sua essência material, a fim de se evitar uma restauração intervencionista que mascara uma realidade social e desconfigura a arte e a história, produzindo apenas embalagens visuais (TUAN, 2011).

Ressalte-se que o monumento, no século XVIII, recebe a denominação de Monumento Histórico, justificada pelo avanço da compreensão da sociedade sobre a relevância atribuída à arte e ao conhecimento sobre uma obra, além de perceber o uso desta, como um recurso e marca para confirmação de inúmeras ações, retratos sociais em uma escala espaço-temporal que, inclusive, se pode fazer permanente, assumindo o valor de um recurso pedagógico (CERQUEIRA, 2006).

É relevante assinalar, por outro lado, que a história da França, no que concerne aos monumentos históricos, a partir dos séculos XVI e XVIII, tem nos donos de antiquários e nos arquitetos, os estudiosos que se propuseram a analisar, com todo o cuidado, os vestígios das obras greco-romanas e que lamentavam sua degradação e abandono na época, pois justamente em função do intenso processo de vandalismo que sofreram os monumentos religiosos na Idade Média, o apelo afetivo teve que se institucionalizar como base para a permanência de uma história material. Nesse contexto, ações de proteção e de restauração de várias obras passaram a ser implementadas, adotando-se uma série de pré-requisitos em termos do ano, estilo da arte e do conhecimento embutido em cada traço de um objeto, o que ressalte-se-, significou um grande avanço na história dos monumentos (CHOAY, 2006).

A perda de muitas igrejas, estátuas e diversos objetos que retratavam fatos, poderes e a memória da sociedade francesa é atribuída aos saques e vandalismo que ocorreram na Revolução (1789-1799), embora este movimento tenha, contraditoriamente, inaugurado, também, um olhar mais atento para as obras e sua proteção. Pois, esse processo 
ALVES. R. C.; SOUZA DE DEUS, J. A.

Memória, afeição ao lugar e política: um olhar sobre o patrimônio em seus enredos derivados da geograficidade humana

histórico invulgar deu origem à consolidação da conservação dos monumentos históricos, (fundamentada nas análises dos elementos que constituíram os objetos e a sua historiografia, numa abordagem que procurava dimensionar sua representatividade para o país), principalmente em 1795, marco do processo institucional da preservação, derivado da Revolução Francesa, pois foi:

Durante essa Revolução que muitos monumentos foram destruídos, pois carregavam valores simbólicos de uma determinada época e cultura que se desejava modificar. E a partir deste processo, a preservação passou a ser vista como necessária derivada da sua perda, e surgiram as determinações de proteção dos monumentos históricos [...] (CERQUEIRA, 2006, p.05).

Esse processo foi importante para a França, uma vez que data de 1830 a primeira instituição da Comissão de Monumentos Históricos no país, implementada com o objetivo de organizar e repensar as formas de reconhecimento, ordenamento e considerações dos elementos monumentais. Neste momento - vale ressaltar -, a conservação dos antiquários dava passagem para uma conservação material dos monumentos históricos em sua conservação real (SILVA, 2003).

E diante do processo "revolucionário" que se intensificava no país (para reorganizar a sua estrutura econômica e política) as obras conservadas tomaram dois caminhos. O primeiro foi à transferência dos bens da Igreja, da Coroa e dos emigrados para o novo comando da nação que ali se instala então. E o segundo, foi à destruição das obras, enquanto imagem-objeto, o que marcou "negativamente" a vida da população. Ou seja, no período verificava-se que cada elemento deveria ser analisado minuciosamente diante da relevância que este assumisse para a sociedade, como uma relação de herança, atrelada à conservação e com uma conotação de espólio nacional (CHOAY, 2006).

Mas, pelo Decreto de 13 de Outubro de 1832, a Comissão dos Monumentos, devendo tombar as diferentes categorias de bens recuperados pela nação, destacou os monumentos em forma de seções para sua organização, tal como as seções de velo direcionadas aos livros, manuscritos, faróis e selos, medalhas, pedras, estátuas, quadros, máquinas, objetos relacionados à cultura e à história natural. Porém, como o Estado estava passando, então, por sérias dificuldades financeiras, a solução encontrada para superar o impasse foi concretizar a venda de alguns monumentos para obter recursos. Nessa ocasião, se 
ALVES. R. C.; SOUZA DE DEUS, J. A.

Memória, afeição ao lugar e política: um olhar sobre o patrimônio em seus enredos derivados da geograficidade humana

procedeu ainda à definição de duas categorias de monumentos históricos que seriam: as básicas (móveis), e as completas (os imóveis) (CHOAY, 2006).

Os móveis foram transferidos para os depósitos provisórios e abertos à visitação pública - ato que Choay (2006) consagra como correspondente à do contemporâneo “museum” que tem a função principal de instruir e servir de espaço para a lembrança social de uma comunidade em seu processo constante de reflexão (ressaltando-se, contudo, que os antiquários constituíam um apanágio de poucos, mesmo em termos de visitação). Já os bens imóveis, tais como conventos, igrejas, castelos, residências de personalidades, estavam com problemas do ponto de vista da manutenção e tais monumentos foram refuncionalizados, então, como depósitos (de munição, de sacas de sal, madeiras e armas).

Num momento histórico subsequente, com o advento da era industrial, e com a progressão das transformações, modelações e também das degradações do meio ambiente, o ato de construir passa a ser um processo de avanço estético e de sobrevivência de mercado, na qual a ruptura dos modos tradicionais de edificar interveio nos valores dos monumentos históricos, em termos de valores da sensibilidade, da estética e da história como justificativas de preservar. Ao pontuarmos isto, não estamos destacando que os novos monumentos, edifícios, prédios, paisagens culturais são menos importantes para os homens que passam a gerir a sociedade, em determinado momento, mas que alguns monumentos são marcas de acontecimentos sociais que merecem ser preservados por remeterem a conquistas sociais (SIMÃO, 2001).

A $2^{\mathrm{a}}$ Revolução Industrial representou um conjunto significativo de mudanças tecnológicas com profundo impacto no processo produtivo, o qual se expandiu por todo o mundo, principalmente a partir da segunda metade do século XIX, desencadeando ritmos de mudanças sociais diferentes em cada lugar; e foi nesse momento que os assuntos e os temas relacionados à identidade começaram a tomar mais corpo quanto à preocupação voltada para o monumento histórico, valendo ressaltar, ainda, que esta revolução (cuja expansão pelo mundo ocorreu de 1830 a 1929) não foi um processo que desencadeou a leitura do monumento histórico de forma isolada (depois do aparecimento da modernidade técnica), mas que representou o reconhecimento da natureza da história do homem que é diariamente modificada e merece ser devidamente cuidada. Pois é nesse momento que a preservação de conjuntos urbanos começa a ser efetivamente pensada, derivada do processo da demolição, 
ALVES. R. C.; SOUZA DE DEUS, J. A.

Memória, afeição ao lugar e política: um olhar sobre o patrimônio em seus enredos derivados da geograficidade humana

padronização e funcionalidade que os Estados queriam realizar em seus territórios (CERQUEIRA, 2006).

E é também nesse contexto que a consagração do monumento histórico aparece na França (entre 1820 a 1960), tal processo, sugestivamente, desenvolvendo-se em paralelo com a confrontação estabelecida entre o reconhecimento dos valores nacionais e históricos dos edifícios e as exigências progressivamente colocadas, então, pela dinâmica da industrialização desordenada, E é interessante notar que, nessa conjuntura, acabam também “[...] ocorrendo mudanças, não somente na arquitetura, nas formas materiais, mas, sobretudo, no modus vivendi [...]" (SIMÃO, 2001, p. 23, grifo do autor).

Françoise Choay (2006) desdobra o momento da referida revolução em dois principais aspectos a serem averiguados e/ou decodificados. O primeiro, em termos da Cultura (no que concerne ao patrimônio); e o segundo, derivado da sua degradação/ depredação. Pois nesse momento de demasiada destruição dos monumentos históricos, a proteção destes elementos passa a ser também exigida em escala nacional e internacional. Se pensarmos na França, os centros urbanos antigos foram aí percebidos num primeiro momento como ultrapassados, em consonância com os anseios da "modernidade", principalmente na era da industrialização; tendo ocorrido, no período, a eliminação ou destruição de muitos monumentos para o alargamento das vias, além dos parcelamentos do planejamento urbano para a implantação de obras (GASTAL, 2006).

Mas foi, também, na França, em 1887, que se promulgou a primeira lei sobre o Monumento Histórico, com o decreto da criação do cargo de inspetor, num processo centralizador de instituição de dispositivos para a proteção dos edifícios tombados, além de se procurar garantir o apoio de fundos do Estado para sua manutenção e restauração. E tais avanços modificaram a estrutura, percepção e funcionalidade dos monumentos históricos no país, que, aos poucos, também incidiram em outras nações. Outro evento importante para se pensar, no que concerne à preservação dos monumentos históricos, ocorreu com a maciça destruição de tais elementos, em alguns casos tendo sido aniquilados conjuntos urbanos completos, corresponde ao conturbado e violento período da Segunda Guerra Mundial (19391945), quando, sucederam-se “[...] grandes mudanças, contudo, de ordem econômica, política, social e cultural. E foi a partir de então é que se deflagrou o processo de discussão sobre a proteção patrimonial e a sua importância indiscutível” (CERQUEIRA, 2006, p.06). 
ALVES. R. C.; SOUZA DE DEUS, J. A.

Memória, afeição ao lugar e política: um olhar sobre o patrimônio em seus enredos derivados da geograficidade humana

A eminente pesquisadora, norte-mineira, Maria Geralda de Almeida coloca em evidência, a propósito, que após a Segunda Grande Guerra houve, no campo de estudo do monumento histórico, uma grande expansão cronológica, tipológica e geográfica do sentido de se perceber a história, principalmente no que concerne às paisagens (arquitetura). A pesquisadora ainda destaca que a forma de se apreender o monumento deixa, a partir de então, de ser elitista e este passa a ser percebido como uma urgência identitária. E tal compreensão passa exatamente a existir quando a sensibilidade monumental é evidenciada (não compreendida como um resgate, mas, sim, como a aquisição de um novo sentido seu para o homem). Nesta compreensão é que, Almeida (2012, p. 150) destaca que a sensibilidade é progressivamente experimentada e:

[...] deixa de ser uma essência da cultura aristocrática para expandir-se para além dos pertencimentos de classes sociais e para além das fronteiras geográficas entre o mundo rural e o mundo urbano. Os processos e práticas culturais começaram, lentamente, a ser vistos como bens patrimoniais, sem necessidade da mediação de objetos. Essa nova percepção surgiu da influência da prática de preservação oriunda de países asiáticos e dos países pré-industriais.

É relevante assinalar que o ano de 1931 constituiu um marco para a discussão dos monumentos, pois nesta data foi realizada a Primeira Conferência Internacional Relativa aos Monumentos, em Atenas, a qual ajudou a difundir propostas de conscientização e de integração dos monumentos, no que se refere a seu uso e processo de conservação. Nesse encontro, foi divulgada ainda a carta patrimonial de Atenas (com a participação de 24 países) que valoriza as manifestações humanas no mundo das artes, no contexto da arquitetura, da música, literatura, dentre outros. Este encontro se fortaleceu com a realização do Primeiro Congresso Internacional de Arquitetura Moderna (CIAM) que discutia a importância da preservação dos monumentos (GHIRARDELLO \& SPISSO, 2008).

O encontro do CIAM foi bem-sucedido, e em 1933 o terceiro encontro realizouse, na ocasião em que se discutia uma nova maneira de se viver na cidade, conforme o uso racional do solo urbano, decorrente dos avanços técnicos que a arquitetura adquiria, levandose em consideração as novas formatações que a cidade teria que perceber e a elas se adequar em suas funções básicas (habitação, lazer, trabalho e circulação), introduzindo, em paralelo, um legado para o monumento histórico das cidades - cidades estas, que não são intocadas, mas, pelo contrário, nesse momento admitem a introdução, em sua dinâmica interna, da vida 
ALVES. R. C.; SOUZA DE DEUS, J. A.

Memória, afeição ao lugar e política: um olhar sobre o patrimônio em seus enredos derivados da geograficidade humana

moderna tentando-se, contudo, conciliar a preservação dos monumentos com a vida que tende a ser desenvolvida em seu entorno - e entendendo que os " [...] núcleos urbanos preservados são cidades como todas as outras, complexas, dinâmicas e simbólicas. E reduzi-las a objetos estanques, as obras de arte, constitui um equívoco sem tamanho" (SIMÃO, 2001, p. 59).

A Carta de Atenas, em sua "doutrina" (nos princípios gerais), destaca que qualquer que seja a reconstituição do monumento, é imprescindível a sua manutenção e restauração, com respeito à obra histórica e artística sem prejudicar o estilo da época em que foi construída. O documento destaca, ainda, que não devem ser vetadas novas construções em sítios urbanos tombados (sobretudo na vizinhança dos monumentos antigos, cuja proximidade deva ser objeto de cuidados), embora nas condições da vida moderna os monumentos, no mundo inteiro, se achem cada vez mais ameaçados (IPHAN, 2012).

Já a Carta de Veneza, divulgada no II Congresso Internacional de Arquitetos e Técnicos de Monumentos Históricos, em 1964, destaca a conservação, restauração e o ambiente em que os monumentos se encontram, reforçando a preocupação com os monumentos avariados na Segunda Guerra Mundial; postulando ser uma responsabilidade de toda a humanidade a salvaguarda das obras monumentais, pois se compreendeu então que o monumento faz parte do meio em que o homem vive, podendo este utilizá-lo. Ou seja, foi aí que deu se fim à ideia de "musealização" do monumento, principalmente na área urbana, passando ele a ser considerado útil à sociedade com outras funções; e devendo acompanhar e se sintonizar com as necessidades modernas das populações (SILVA, 2003).

A conservação dos monumentos é tratada num artigo especial (artigo $5^{\circ}$ ) nesta carta, em que se aborda a possibilidade de o monumento ser socialmente funcional, uma vez que “[...] tal utilização é, portanto, desejável, mas não deve alterar a disposição interna ou a decoração do edifício. E é dentro destes limites que as modificações necessárias para a alteração de funções devem ser encaradas [...]" (ICOMOS, 2007, p. 02); ou seja, a conservação também se baseia na funcionalidade dos prédios e monumentos, e o uso dos monumentos deve "se harmonizar" e estar acoplado ao ato de preservação. Vale assinalar que alguns autores, tais como Costa (2009), identificam nesta carta o marco simbólico que também aproxima o monumento histórico de uma mercadoria.

Logo o documento da Recomendação de Paris de Obras Públicas ou Privadas, em 1969, reforça a importância do uso dos monumentos históricos, como os grandes casarões, 
ALVES. R. C.; SOUZA DE DEUS, J. A.

Memória, afeição ao lugar e política: um olhar sobre o patrimônio em seus enredos derivados da geograficidade humana

pois a civilização contemporânea não se repousa nas tradições culturais, mas também as cria, transforma com o desenvolvimento econômico, num processo, contudo, em que os governos, Estados, devem assegurar a proteção e a preservação da herança cultural da humanidade, respeitando as novas gerações precisamente através dos incentivos aos seus monumentos (IPHAN, 2012).

Focalizando agora tais dimensões da realidade num período mais recente, vale destacar que no século XX, entre o final da década de 60 até 1980, as cidades sofreram mudanças estruturais mais visíveis, como as implantações aí de maiores empreendimentos industriais, o grande desenvolvimento de vias de acesso, apoio aos transportes públicos, aumento da telecomunicação, dentre outros. E diante de tantas mudanças, Cerqueira (2006, p.15) destaca que foi necessária uma nova força para se preservar os monumentos históricos, pois “[...] as modificações feitas em nome do progresso fizeram, muitas vezes, as cidades perderem suas referências simbólicas. Estas perdas foram determinantes para o surgimento do grande interesse em preservar o patrimônio cultural, alimento da memória”.

Com tantas mudanças sociais, e, sobretudo, geográficas ocorrendo no mundo, foi realizada, por sua vez, na França, em 1972, a Convenção Relativa à Proteção do Patrimônio Mundial, Cultural e Natural, com o patrocínio da Organização das Nações Unidas para a Educação, a Ciência e a Cultura (UNESCO), com o objetivo de elaborar medidas a serem adotadas por todos os países-membros no sentido de coibir a exportação e transferências de bens culturais, além de promover a proteção dos bens culturais imóveis. Nesse momento, os monumentos históricos foram também reconhecidos como Patrimônios, podendo eles, definitivamente, passarem a funcionar como um serviço público de domínio do Estado e com atividades coletivas de recriação, constituindo-se, então, elementos que tendem a ajudar na sua preservação e conservação (UNESCO, 2005).

E Cerqueira (2006, p. 05), nesse sentido, salienta que “[...] na década de 70, o patrimônio é percebido como um elemento que promove a continuidade da vida em seus usos e funções sociais. A preservação deixa de ser o congelamento de um tempo e torna o lugar de fatos sociais e acontecimentos culturais". Além desse avanço, compreende-se o monumento como bens culturais que são: monumentos e os conjuntos (SILVA, 2003). O autor destaca que os monumentos são obras arquitetônicas, de escultura ou de pinturas monumentais, inscrições, cavernas e grupos de elementos que tenham um valor universal de grandeza excepcional do 
ALVES. R. C.; SOUZA DE DEUS, J. A.

Memória, afeição ao lugar e política: um olhar sobre o patrimônio em seus enredos derivados da geograficidade humana

ponto de vista da história, da arte e ou da ciência. Já os conjuntos são definidos como grupos de construções isoladas ou reunidas, que, em virtude de sua arquitetura, são destacadas na paisagem (SILVA, 2003). E tais conjuntos merecem destaque, pois são incluídas nessa classificação as cidades mortas, históricas vivas e novas do século XX, devendo-se se pontuar que as cidades mortas são aquelas que não possuem vida contemporânea sendo, portanto, desabitadas; enquanto as históricas vivas são aquelas que possuem funções contemporâneas sem perder os traços passados como é o caso de Diamantina/MG. E as novas, do século XX, são as que apresentam traçados da modernidade, tal como Brasília/DF (SILVA, 2003).

É pertinente demarcar ademais que para um elemento constar na lista de bens culturais do patrimônio mundial da humanidade, ele tem que ser diagnosticado como de expressão única, tanto no mundo das artes, como do conhecimento e de ligação afetiva. Verifiquemos as diretrizes norteadoras que a instituição define para tal:

(i) representar uma realização artística única, uma obra-prima do gênio criativo humano ou;

(ii) exercer grande influência, por um período ou dentro de uma área cultural específica do mundo, a respeito do desenvolvimento da arquitetura, das artes monumentais, do planejamento de cidades ou do modelo de paisagens, ou;

(iii) representa um testemunho especial ou no mínimo excepcional de uma civilização ou tradição cultural desaparecida.

(iv) é um excepcional exemplo de um tipo de construção ou conjunto arquitetônico ou paisagem que ilustre significativamente os estágios da história humana, ou;

(v) é um exemplo excepcional de ocupação humana tradicional ou de uso de terra representativo de uma cultura [...].

(vi) é direta ou claramente associado com eventos ou tradições vivas, com idéias ou com crenças, com obras artísticas e literárias de importância universal excepcional [...] (SILVA, 2003, pp.93-94).

Essa universalização dos monumentos foi impulsionada pelo valor intrínseco deles próprios, que ficou bem demarcado na Convenção Relativa à Proteção do Patrimônio Mundial Cultural e Natural, adotada em 1972, pela Assembleia Geral da UNESCO, e foi reafirmado na Convenção do Patrimônio Cultural Mundial em 1990. Nesse contexto é que se firmou o conceito de Patrimônio Cultural Universal, proclamando a universalidade do sistema ocidental de pensamento e valores sobre o vasto espectro de referências a respeito do que seja e para que serve o Patrimônio. Além desse avanço, novas possibilidades de inscrição de bens como patrimônios mundiais se concretizaram, a partir daí, em duas categorias: a natural e a cultural (UNESCO, 2005). 
ALVES. R. C.; SOUZA DE DEUS, J. A.

Memória, afeição ao lugar e política: um olhar sobre o patrimônio em seus enredos derivados da geograficidade humana

Em termos conceituais, destaca-se que Patrimônio Cultural abrange "[...] todos os bens materiais e imateriais, naturais ou construídos que uma pessoa ou um povo possui ou consegue acumular" (GHIRARDELLO \& SPISSO, 2008, p.13), que tenham valor excepcional para a Ciência, a Arte e para o conhecimento histórico dos homens, tendo como referência o seu estudo de caráter etnológico e antropológico. Nessa perspectiva, expande-se, aliás, a tipologia do patrimônio que pode ser considerado como um conjunto dos bens culturais que se referem às identidades de um grupo de indivíduos ou mesmo de sociedades inteiras. Choay (2006, pp. 12-13) destaca que o domínio patrimonial não se limita aos edifícios particulares, “[...] ele compreende os aglomerados de edificações e a malha urbana: aglomerados de casas e bairros, aldeias, cidades inteiras e mesmo conjuntos de cidades, como mostra a lista do Patrimônio Mundial”.

Sobre a paisagem, como marca de uma vida, foi somente na Conferência das Nações Unidas sobre o Meio Ambiente e Desenvolvimento, realizada na cidade do Rio de Janeiro, em 1992, é que a UNESCO institucionalizou a categoria de paisagem cultural. A partir de então, oficialmente a paisagem é um bem aliado aos elementos materiais e/ou naturais, sendo patrimônio relacionado aos sentidos subjetivos que nela residem. Tal definição foi um passo significativo para uma nova abordagem do que seja o patrimônio, pois como sinaliza Isabelle Cury, arquiteta do IPHAN, (2012, p.02), este foi um momento em que saímos "[...] de um contexto que utilizava o termo como referência à atribuição de valor de um bem, para a identificação dos valores atribuídos pelos grupos culturais aos diversos elementos que constituem uma determinada paisagem".

No enfoque da UNESCO, a influência dos vários atores na instituição fica evidente quando se observam as classificações que são direcionadas a ela, subdivididas em três categorias, a saber: $(i)$ as paisagens claramente definidas, aquelas que foram realizadas pelos homens, sendo a sua obra observada de forma real; (ii) as paisagens evoluídas organicamente, ou seja, as que estão em processo de evolução, conhecidas, também como paisagens vivas e; por fim, (iii) as paisagens culturais associativas, as que integram a construção do Homem e da Natureza (CURY, 2012). Essas classificações ganham visibilidade e emprego em diversas abordagens da Ciência, extrapolando, assim, a sua aplicação nos estudos sobre o patrimônio, o que caracteriza um avanço, principalmente ao discutir os feitos do homem na paisagem. 
ALVES. R. C.; SOUZA DE DEUS, J. A.

Memória, afeição ao lugar e política: um olhar sobre o patrimônio em seus enredos derivados da geograficidade humana

Em outubro de 2011, na 36ª Conferência Geral da UNESCO, outro avanço se deu - no que diz respeito ao conceito de paisagem -, no contexto de sua compreensão enquanto patrimônio, através da aprovação do documento "Recomendação sobre as Paisagens Históricas Urbanas" no qual se afirma que a paisagem urbana somente pode ser compreendida como histórica quando existe a apreensão do ambiente e de seu contexto memorial por meio da percepção sensorial, firmando a importância desta enquanto um arsenal do patrimônio cultural (CURY, 2012).

O número de bens que constam na lista do Patrimônio Mundial até 2018 é de 962 sítios, sendo: 745, culturais; 188, naturais; e 29, mistos e estando eles localizados em 153 Estados-Nações diferentes. Até o mês de julho de 2015, 189 Estados já haviam ratificado a Convenção do Patrimônio Mundial, promovendo um trabalho frutífero que envolve a colaboração dos governos de cada um destes Estados e os órgãos responsáveis pela proteção e monitoramento dos bens - bens estes que vão desde o patrimônio histórico, natural, imaterial, destacando as tradições orais, à cultura e a arte popular em suas mais diversas manifestações (UNESCO, 2013).

O Brasil está entre os países que percebe o valor de inscrever o(s) seu(s) patrimônio(s) na lista do Patrimônio Mundial, contemplando 19 bens inscritos, conseguindo se destacar enquanto Estado que valoriza a cultura nacional. E a manifestação mais clara desta realidade se concretiza com a atribuição à cidade do Rio de Janeiro do título de primeiro Patrimônio Mundial incluído na categoria paisagem cultural urbana, o que foi aprovado na $37^{\text {a }}$ Sessão do Comitê do Patrimônio Mundial, ocorrida no mês de julho de 2012, em São Petersburgo, na Rússia, tendo sido usados como critérios para isso as seguintes diretrizes da UNESCO: $(i)$ a representação de uma obra prima de um gênio criativo; (ii) o caráter de tal paisagem como testemunho de um intercâmbio de influências considerável, durante um dado período ou numa determinada área cultural, no que concerne ao desenvolvimento da arquitetura ou da tecnologia, das artes monumentais, do planejamento urbano ou da criação de paisagens e, $(v i)$ a associação direta ou material a acontecimentos ou tradições vivas, ideias, crenças ou obras artísticas e literárias de significado universal (IPHAN, 2012).

Segundo discrimina o IPHAN (2018), os locais das cidades valorizadas com o título se constituirão alvo de ações integradas, visando à preservação da sua paisagem cultural, a exemplo - no Rio de Janeiro -, do Pão de Açúcar, Corcovado, Floresta da Tijuca, 
ALVES. R. C.; SOUZA DE DEUS, J. A.

Memória, afeição ao lugar e política: um olhar sobre o patrimônio em seus enredos derivados da geograficidade humana

Aterro do Flamengo, Jardim Botânico, Praia de Copacabana e a entrada da Baía de Guanabara. As belezas cariocas incluem ainda o Forte e o Morro do Leme, o Forte de Copacabana e o Arpoador, o Parque do Flamengo e a Enseada de Botafogo. Além da paisagem cultural da cidade, o Brasil tem outros 18 bens, entre culturais e naturais, na lista dos bens reconhecidos pela UNESCO.

Os bens culturais no Brasil, que são contemplados na lista do patrimônio mundial, são: Conjunto Arquitetônico e Urbanístico de Ouro Preto/MG (1980); Centro Histórico de Olinda/PE (1982); Ruínas de São Miguel das Missões/RS (1983); Santuário do Bom Jesus de Matosinhos, em Congonhas/MG (1985); Centro Histórico de Salvador, Bahia (1985); Conjunto Urbanístico de Brasília/DF (1987); Centro Histórico de São Luís do Maranhão (1997); Centro Histórico de Diamantina/MG (1999); Centro Histórico de Goiás-(2001) e; Praça de São Francisco, em São Cristovão/SE (2010). E os bens naturais inscritos são: Parque Nacional do Iguaçu/PR (1986); Costa do Descobrimento, sul da Bahia e Espírito Santo (1997); Parque Nacional Serra da Capivara/PI (1998); Reserva da Mata Atlântica, São Paulo e Paraná (1999); Parque Nacional do Jaú/ AM (2000); Pantanal mato-grossense, Mato Grosso e Mato Grosso do Sul (2000); Reservas do Cerrado: Parque Nacional dos Veadeiros e das Emas/GO (2001) e Parque Nacional de Fernando de Noronha/PE (2001) (IPHAN, 2018).

É relevante assinalar que a grande questão envolvida no processo de colocar em evidência o patrimônio relaciona-se com o ato de pensar sobre a nossa realidade enquanto nação e seus/nossos projetos políticos. Pois, o patrimônio representa sempre um desafio de leitura do tempo em que a gente vive, ao nos incitar a perceber a ideia de unidade a partir da pluralidade, na medida em que compartilhamos histórias em um mesmo território, mas somos inseridos em diferentes culturas e o que nos une enquanto sujeitos que investigam a importância dos bens culturais é a diferença, que ao mesmo tempo nos distancia e nos aproxima.

\section{CONSIDERAÇÕES FINAIS}

No processo de construção das reflexões teórico-conceituais, aqui esboçadas, verificamos a pertinência da utilização dos paradigmas de interpretação da Geografia Cultural e Percepção Ambiental / Geografia das Representações para abordar, com propriedade, os conceitos e temas sobre os quais problematizamos neste ensaio, ainda que efetivadas em 
ALVES. R. C.; SOUZA DE DEUS, J. A.

Memória, afeição ao lugar e política: um olhar sobre o patrimônio em seus enredos derivados da geograficidade humana

diálogo e interlocução, numa perspectiva interdisciplinar, com outros campos do Conhecimento científico, os quais também colocam em pauta (e em evidência) tais recortes.

Vale ressaltar ainda que quando abordamos a formação e ideia de patrimônio histórico muitos poderão se surpreender se esperam de nós uma leitura e posicionamento muito lineares do processo histórico de formação do pensamento sobre o patrimônio no Mundo e no Brasil, e ao se defrontar, ao contrário, com análises as quais se pretende abrangentes, plurais. Uma delas diz respeito ao entendimento do patrimônio como algo que tem mais relação com o presente do que com o passado, o que por sua vez vincula-se à capacidade que temos de criticar, analisar e ressignificar o sentido amplo de um bem cultural.

\section{REFERÊNCIAS}

ALMEIDA, Maria Geralda. Patrimônio e meandros políticos para pensar sua gestão. OLAM - Ciência \& Tecnologia, Rio Claro (SP), ano XII, pp.148-166, jan./dez. 2012.

ALVES, Renato. Os 10 hábitos da memorização: desenvolva uma memória de elefante. São Paulo (SP): Gente, 2009. p.11-19.

CERQUEIRA, Letícia Mourão. Patrimônio cultural, políticas urbanas e de preservação: os casos de Diamantina/MG e Tiradentes/MG. 2006. 378 f. Dissertação. Programa de Pósgraduação da Escola de Arquitetura. Universidade Federal de Minas Gerais, Belo Horizonte (MG), 2006.

CHOAY, François. A alegoria do patrimônio. Tradução de Luciano Vieira Machado. 4. ed. São Paulo (SP): Estação Liberdade; UNESP, 2006. 282 p.

COSTA, Everaldo Batista. A dialética da construção destrutiva na consagração do Patrimônio Mundial. São Paulo (SP): Humanitas: FAPESP, 2009. 308p.

CURY, Isabelle. A construção do conceito de Paisagem Histórica Urbana. In.: $2^{\circ}$ Colóquio Ibero-Americano: Paisagem cultural. Belo Horizonte (MG) [Anais...], 2012. p. 01-15.

FUNARI, Pedro Paulo; PELEGRINI, Sandra de Cássia Araújo. Patrimônio Histórico e Cultural. Rio de Janeiro (RJ): Jorge Zahar, 2006. 72 p.

GASTAL, Suzana. Alegorias urbanas: o passado como subterfúgio. Campinas (SP): Papirus, 2006. 220 p.

GHIRARDELLO, Nilson; SPISSO, Beatriz. Patrimônio histórico: como e por que preservar. Grupo de Trabalho Patrimônio Histórico e Arquitetônico. Conselho Regional de Engenharia, Arquitetura e Agronomia do Estado de São Paulo. Bauru (SP): Canal 6, 2008. 36 p. 
ALVES. R. C.; SOUZA DE DEUS, J. A.

Memória, afeição ao lugar e política: um olhar sobre o patrimônio em seus enredos derivados da geograficidade humana

GONÇALVES, José Reginaldo Santos. Monumentalidade e cotidiano: os patrimônios culturais como gênero de discurso. In: OLIVEIRA, Lúcia Lippi (Org.). Cidade: história e desafios. Rio de Janeiro (RJ): Fundação Getúlio Vargas, 2002. p.108-123.

ICOMOS. Carta internacional sobre a conservação e o restauro dos monumentos e dos sítios. Ministério da Cultura. Instituto do Patrimônio Histórico Artístico Nacional. Brasília (DF), 2007.

IPHAN. Comitê técnico da candidatura do Rio à Patrimônio Mundial. Ministério das Relações Exteriores. Ministério da Cultura. Instituto do Patrimônio Histórico Artístico Nacional. Brasília (DF), 2012. 335 p.

IPHAN. Cidades e os seus patrimônios. Ministério da Cultura. Cultura. Instituto do Patrimônio Histórico Artístico Nacional. Brasília (DF), 2018. 131 p.

LIMA, Fernanda Pedrosa. Diagnóstico sobre a institucionalização e a efetividade do planejamento em municípios históricos: "Diamantina e Tiradentes". 2008. 310f.

Dissertação (Mestrado). Universidade Federal de Minas Gerais, Belo Horizonte (MG), 2008.

NASCIMENTO, Ricardo Pereira. Revoluções e pensamentos em guerra: Algumas leituras. Campinas (SP): Papirus, 2011. 178 p.

SILVA, Fernando Fernandes. As cidades brasileiras e o Patrimônio Cultural da Humanidade. São Paulo (SP): EdUSP, 2003. 204 p.

SIMÃO, Maria Cristina Rocha. Preservação do patrimônio cultural em cidades. Belo Horizonte (MG): Autêntica, 2001. 102 p.

TUAN, Yi-Fu. Espaço, tempo, lugar: um arcabouço humanista. Tradução de Werther Holzer. Geograficidade, v.01, n.01, p.08-19, 2011.

UNESCO. Patrimônio mundial no Brasil. $3^{\mathrm{a}}$. Edição. Ministério da Cultura. Caixa Econômica Federal. Brasília (DF), 2005. 107 p.

UNESCO. Textos fundamentais da Convenção do Patrimônio Mundial de 1972. Ministério da Cultura. Caixa Econômica Federal. Brasília (DF), 2013. 104 p. 
ALVES. R. C.; SOUZA DE DEUS, J. A.

Memória, afeição ao lugar e política: um olhar sobre o patrimônio em seus enredos derivados da geograficidade humana

\section{Autores}

Rahyan de Carvalho Alves - Possui Graduação em Geografia pela Universidade Estadual de Montes Claros (UNIMONTES), Mestrado em Geografia pela Universidade Federal de Minas Gerais (UFMG). Atualmente é Professor da Universidade Estadual de Montes Claros (UNIMONTES) e cursa Doutorado pelo Programa de Pós-Graduação em Geografia da Universidade Federal de Minas Gerais (UFMG).

José Antônio Souza de Deus - Possui Graduação em Geologia pela Universidade Federal de Minas Gerais (UFMG), Mestrado e Doutorado em Geografia pela Universidade Federal do Rio de Janeiro (UFRJ). Atualmente é Professor do Programa de Pós-Graduação em Geografia da Universidade Federal de Minas Gerais (UFMG).

Artigo recebido em: 10 de fevereiro de 2020.

Artigo aceito em: 10 de junho de 2020.

Artigo publicado em: 30 de junho de 2020. 